\title{
Conceptualizing Challenges to Electronic Human Resource Management (e-HRM) Adoption: A case of Small and Medium Enterprises (SMEs) in Tanzania
}

\author{
Namrata Harsheel Shah, Francis Michael (Ph. D) and Henry Chalu (Ph.D) \\ University of Dar es salaam, Tanzania \\ Corresponding author's email: namrata.tolia9 [AT] gmail.com
}

\begin{abstract}
Most of the Small and Medium-sized Enterprises (SMEs) in the developing countries are yet to espouse and witness the full potential of electronic Human Resource Management (e-HRM) in their business operations despite its popularity in the developed countries. SMEs indispensable role in economic growth regarding employment creation and their contribution to GDP is globally acknowledged. A successful adoption of e-HRM may be the catalyst for the growth of Tanzania and many developing countries. Unfortunately, the application of e-HRM by the SME sector in Tanzania lacks depth and has been scrimpy. Numerous reasons and factors account for the low adoption rate of e-HRM by Tanzanian SMEs. This study aspires to address this scantiness by investigating e-HRM adoption to overcome the barriers that confront the SME sector in their quest to adopt e-HRM. Financial barrier was the most relevant among the five group of barriers. However, technical and Internet security prove to impede the adoption too. Thus to stimulate the adoption of e-HRM to increase productivity and enhance global competiveness, stakeholders and the government should invest in e-HRM and its components. Specifically, the paper delineates challenges of e-HRM adoption. A systematic desk review presents the evolution of prominent TAM model to fit contextual requirements and research advancement. This review thus culminates in a synthesized conceptual framework useful in research on e-HRM in the SMEs.
\end{abstract}

Keywords---- Challenges, e-HRM, SME, adoption

\section{INTRODUCTION}

With increased growth in e-businesses among various sectors, it is necessary to find an electronic infrastructure in organizations, along with an integrated electronic management, to automate the workflow in accordance with the systematic electronic applications. Countries are taking large initiatives in the development of e-business, including but not limited to, the United Arab Emirates, Egypt, Jordan, Lebanon, but that these initiatives need to deepen and follow-up, speed and greater funding than is dedicated to it now if they are to keep up with what is happening globally, especially in terms of $\mathrm{R}$ and $\mathrm{D}$ support, without which it cannot accommodate the right of endemic or absorption in this new economy (Abdalkrim, 2012). Considerable indecisiveness remains, however, as what is the level of connection between Electronic Human Resource Management (e-HRM) use and company's performance, if e-HRM adoption have beneficial connection or not and either complementarities among Human Resource (HR) methods can increase business results or not (Abdalkrim, 2012). Institution's e-HRM practices must develop employee's knowledge, skills, and motivation (Dessler, 2013). Human resource management (HR) is facing, whether in the public or private sector in the world, enormous challenges and is on the outskirts of the twenty first century, which is packed with political, economic, social, technological and cultural changes that are rapid and complex changes (Al-Najar, 2008). One of the factors that significantly impact human resource management within this change in environment is technology factor, as the changes that will result because of this factor in the next fifty years is equivalent to the changes that have occurred in this area over the past one thousand years (Mondy and Noe, 2005).

The closing of the twentieth century has given rise to a vast debate concerning the response of human resource management to the changing external and internal environment of the firm. The late 1990s found the literature somehow settled on the necessity of strategic HRM, but concerned about the new roles that the HR function should adopt in order to meet contemporary organizational challenges (Kochan,1997; Ulrich, 1997a, 1998). The strategic role of the HR function means being involved in strategic planning from the outset and not only during the implementation phase and matching employee resources with business needs. This role is expected to occupy significantly more of the HR practitioner's time in the future (Anderson, 1997).However, this does not mean that the administrative role will cease to exist, although there is an inherent tension between the outlook required for a strategic HR role and that of the HR specialist in a traditional role (Beer, 1997).One of the important aspects of the changing environment especially relevant to management is the information revolution. According to Ulrich (1997b), an emerging HR practice area that will require investment of time, talent and 
resources is leveraging technology. Technology comes to the rescue in reducing the tension between the strategic and administrative role, as it has advanced to the point where it can remove part of the administrative responsibility (Ellig, 1997) and renovates the HR. There is a requirement for more investigation into the effect of e-HRM (Strohmeier, 2007). According to Khatoon (2012) e-HRM is a rapidly emerging sensation in the HR arena. It is an extensive sphere where doubts are still unanswered and notions have no significant scientific source. Few of these doubts are concerned with the aspects swaying the adoption of e-HRM and the use of e-HRM (Khatoon, Amin and Hossain; 2013). The practice of technology in HR or HR done by electronic means is called e-HRM (Hopkins and Markham, 2006).

The Small and Medium Enterprise Development Policy of United Republic of Tanzania Ministry of Industry and Trade (2003) express that for SMEs, the presence of a commonly agreed definition does not exist. In the framework of Tanzania, micro enterprises are the ones that engage up to 4 people, in maximum instances family members or engaging capital amounting up to Tanzanian shillings 5.0 million. Small enterprises are generally official endeavors engaging from 5 to 49 personnel or with capital investment between Tanzanian shillings 5 million to Tanzanian shillings 200 million. Medium enterprises engage between 50 and 99 persons or exercise capital investment from Tanzanian shillings 200 million to Tanzanian shillings 800 million (the Small and Medium Enterprise Development Policy of United Republic of Tanzania Ministry of Industry and Trade, 2003). Mukherjee, Bhattacharyya and Bera (2014) put forward that Small and Mediumsized Enterprises (SME) are acknowledged as important for developed and developing economies respectively. For developing nations they are particularly vital as SMEs play crucial part in poverty decline by creating jobs. Currently, to a greater extent SMEs have commenced to practice information technology in their Human Resource Management roles to enhance their management and increase their competence. The chief source of jobs and income in Tanzania is in SMEs. SMEs provide significantly to the economies of the countries, in case of Tanzania around $70 \%$ of all businesses are in SME sector. This illustrates that SMEs account for a superior part of economic activity (Economist Intelligence Unit, 2009). Therefore the SME domain in Tanzania is in charge for managing the lives of millions of individuals. In this regard arises the worth and significance of time invested in SMEs. Therefore, use of technology-based applications in HRM that will assist these enterprises is very critical. Hence challenges to the adoption of such e-HRM applications in HRM are the core measures of this study.

\section{Context of the paper}

The key powers that motivate institutions to take-on Information and Communication Technology (ICT) driven Human Resource (HR) solutions are the necessity for financial stability, quality services, higher performance, and organizational cultural modification (Yeung and Brockbank, 1995). However, many developing nations still lag behind in adopting eHRM systems, in spite of their obvious advantages (Walinda, 2013). Walinda (2013) adds that e-HRM is currently in its initial stages in developing nations.

This study will employ TAM (Technology Acceptance Model) by Davis (1989) which is the most widely cited. Numerous empirical studies have found that TAM consistently explains a substantial proportion of the variance (typically about $40 \%$ ) in usage intentions and behavior, and that TAM compares favorably with alternative models ( Venkatesh, 1999). Therefore TAM is the most appropriate to study adoption of e-HRM in this paper.

E-HRM delivers the HR occupation with the chance to generate novel ways for adding to business effectiveness and efficiency (Lengnick-Hall and Moritz, 2003). On the other hand, HR units yet face troubles with adopting fresh technologies (Martin and Reddington, 2010; Smale and Heikkilä, 2009; Tansley, Newell, and Williams, 2001). According to Kovach and Cathcart (1999) survey report, among other ingredients that slow down the e-HRM adoption is lack of belief in e-HRM technology. Sylvester, Bamidele and Oluyemi (2015) in their examination on e-HRM systems adoption emphasized that the slow growth of e-HRM in developing nations is due to financial issues, behavioral perceptions, lack of enough government support and lack technological expertise and equipment. A latest study in Zimbabwe by Denver, Gibson, Tonderayi and Severino (2018) stated that institutions are failing to adopt appropriate practices in Human Resources Management because employees lack the technical expertise, skills; poor financial budget for technology and organizational management support. Another study in Ghana conducted by Nyame and Boateng (2015) on 129 firms stated that two-thirds of the businesses never adopted Human Resource Information System (HRIS) use due to ignorance and less inclination for technology as one of the few reasons.

Amongst other developing countries there is Tanzanian e-HRM situation where the government of Tanzania took different measures/efforts to ensure that the use of ICT (e-HRM) is achieved. In 2009 the Government looked at adoption and use of ICT (Cumming, 2010). As per Madulu (2016) in his work on adoption of electronic record keeping for human resource management whose findings indicate that some obstacles of e-HRM in Tanzania include shortage of funds, unwillingness of user/employees to use new technology, poor accessibility, poor management support etc. More so, Tanzania faces numerous challenges for use IT (URT, 2009). These issues created attention for research on e-HRM adoption from theoretical and empirical research over time. Specifically, this paper delineates challenges of e-HRM adoption in SME's. To achieve this, the following research question was posed: What are the overall challenges to e-HRM adoption? The main objective of this study was to highlight factors that are barriers to e-HRM adoption. 
Traditional human resources management (HRM) comprises the recruitment, selection, development, compensation, retention, evaluation, promotion etc. of personnel within a business (Bernardin and Russel, 1993), which can be generally shifted to the computer-generated domain. Thus, the HR profession surfaces an imperative task with new E-HRM and virtual engagements faced in the business world. Yet, E-HRM has been known as its position as the dynamic version of HRM. E-HRM roles share parallels with HR management roles, which are planning for organizations and jobs for people, acquiring human resources, building individual and organizational performance, rewarding employees, maintaining human resources (Fisher, Schoenfeldt, and Shaw, 1996). Using E-HRM technology is a technique of implementing HR strategies, policies, and practices. The E-HRM technology supports the HR function to stand by the HR requirements of the organization based on the system (Ruel et al., 2004). The E-HRM technology offers a portal which enables managers, employees, and HR professionals to view, extract, or alter data which is necessary for managing the HR of the organization. HR executives are banking on technology and the information it delivers to benefit them drive decisions that will lead to success of the organization at large. Snell, Stueber, and Lepak (2002) communicate that HR can be more strategic, flexible, cost-effective applied with the E-HRM practice. It has been highlighted that Information Technology (IT) has the prospective to reduce administrative costs, increase productivity, speed response times, enhance decision-making, and improve customer service all at the same time. The need for cost reduction, higher quality services, and cultural change are the three main forces that drive corporations to seek IT-driven HR solutions (Ulrich, Brockbank, Yeung and Lake, 1995). The speedy development of the Internet during the last era has boosted the implementation and application of E-HRM (Strohmeier, 2007). According to Strohmeier (2007), E-HRM is the use of information technology for both networking and supporting at least two individual or collective actors in their shared performing of HR activities. Virtual HR is evolving due to the growing sophistication of IT and amplified external structural options (Lepak and Snell, 1998). Surveys of HR consultants advise that both the number of organizations embracing E-HRM and the depth of applications within the organizations are constantly growing. IT is starting to enable firms to deliver great HR services. Many experts predict that the personal forecast will become the main tool for all HR professionals (Kovach and Cathcart, 1999).

\section{THEORETICAL BACKGROUND AND REVIEW OF LITERATURE}

Technology acceptance theory demonstrates how users come to adopt a technology, i.e. e-HRM in our research. It has been opined that technology is the most influential tool and therefore application of technology acceptance model. The most applicable theory in this paper is technology acceptance model (Davis, 1989; Davis, Bagozzi, and Warshaw, 1989).

\section{Technology Acceptance Model (TAM)}

The Technology Acceptance Model (TAM) is based on two equally connected aspects that form the heart for the attitude in the direction of IT: perceived ease of use (PEOU) and perceived usefulness (PU) (Voermans and Vanvendhoven, 2007). These aspects are hypothesized to establish the behavioral intention to user's acceptance (Davis and Arbor, 1989) which is e-HRM in this study. The researcher's assumption here, is that if e-HRM is perceived well and this technology accepted by the employees then it will lead to adoption and use of e-HRM technology. Perceived usefulness is expressed as the degree to which a person considers that using a specific technology will aid in executing a job well and improve the job performance (Davis et al., 1989). Perceived ease of use talks about the degree to which the prospective user expects the technology to require the least amount of effort (Davis, Bagozzi, and Warshaw 1989; 985). Behavioral intention is a degree of the force of one's intention to perform a stated behavior.

\section{Figure1: The Technology Acceptance Model}

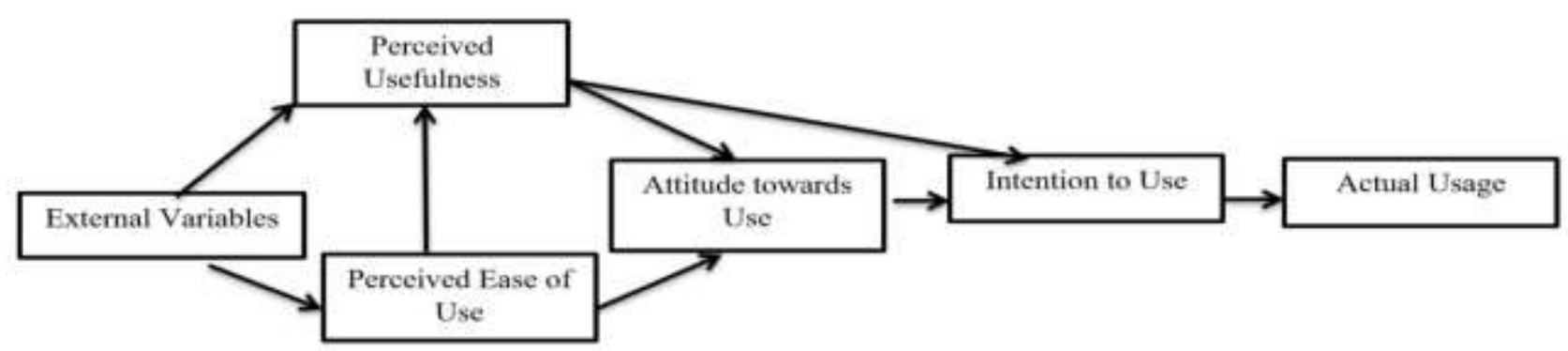

Source: Davis, 1989

As per technology acceptance model, perceived ease of use and perceived usefulness forecast the adoption and acceptance of information technology (Ma and Liu, 2004).

Challenges to e-HRM adoption in Tanzania 
The shift from traditional HRM to e-HRM practices gives rise to several effects on the role of HRM. E-HRM, apart from substantial reductions in cost and time and transition of administrative activities from the HR department to the employees themselves, can bring about an "increased emphasis on HR as a strategic business partner whose primary challenge is to recruit, develop and retain talented employees for the organizations" (Ensher et al., 2002).First, a major effect of the shift from traditional HRM to e-HRM is that it enables HR employees to focus on more strategic, value-added activities. Less administrative and paperwork allows the HR professionals to develop other, more strategic functions of their profession. On the other hand, this may also mean that with the use of e-HRM, fewer HR professionals are needed, because e-HRM eliminates the "HR middleman"(Lengnick-Hall and Moritz, 2003). Therefore, the effect of e-HRM on the HR profession may be seen as both a threat and an opportunity. Second, e-HRM, through self-service, entails increased involvement of employees and managers in HR practices. The employees and general managers become savvier about HR practices and HR devolvement becomes a reality. This distributed knowledge poses the challenge for HR professionals to consistently keep up with new developments in their field, in order to maintain their advisory-consulting role (Ulrich, 2000). Another point that needs to be stressed is that, as e-HRM is more than technology, it calls for competent HR professionals in order to fully benefit from e-HRM adoption and implementation. "Technology itself may be value neutral, but how it is used can greatly impact the role of HR" (Ensher et al., 2002). This can be seen as a further opportunity for the HR profession, to take up the role of the developer of e-HRM functions. It demands, however, that the HR professional also become knowledge able in basic IT issues, so that communication using IT is more productive.

The use of e-HRM in an organization is affected by various factors, which are highlighted by Banerji (2013). They are: orientation of employees, work culture, security concerns, cost factors, trainings, learning's, accessibility, availability of internet and the technical limitations. According to Chinyuka (2018) in his study implementation of human capital management information system in local government of Tanzania the study revealed that some employees had positive perception and others negative perception towards ICT. The study findings also listed a number of challenges associated with the proper functioning of the system while addressing HR information and practices like lack of enough resources to facilitate effective implementation of the system, inadequate knowledge to the system users, poor accessibility etc. In Tanzania, data on the role of e-HRM is scarce (International Records Management Trust, 2007). Past studies have mostly dealt with electronic management in the development of human resources in many organizations in developing countries and return to a lot of reasons, including that the technological infrastructure of these countries has not been completed in such a way to contribute to the administration of electronic process of administrative development where they can address this problem (Khatoon, 2012; Khashman et al., 2015; Ukandu et al., 2014). The cost for future investments and the e-HRM itself is also a major problem. Also, sometimes e-HRM can run into management resistance. The importance of technology for human resource management cannot be ignored because it enhances information sharing, transparency, accountability and more (Asogwa and Ezema, 2012). Different efforts have been undertaken by the Tanzanian government to support ICT for human resource in public and private institutions, such as enacting various laws, regulations, ICT policy. In spite of the different efforts that have been undertaken by the government to ensure technology development, there are many challenges faced by Tanzania with use of e-HRM (Walinda, 2013).

SMEs remain the backbone of many economies as a result of their indispensable role in both wealth and job creation (Okpara and Wynn, 2007). Based on SMEs qualitative and subjective judgment on their categorization, there is no standard definition of SME across the globe as different countries and firms set their own criteria for definition (Kabanda and Brown, 2017). However, the number of employees, turnover and level of assets of a firm are the frequently used criteria in defining SMEs. SMEs play a crucial role in majority economies, especially in developing countries like Tanzania. Formal SMEs subsidize approximately $60 \%$ of total employment and up to $40 \%$ of national income (GDP) in emerging economies like Tanzania, wherein these numbers are extremely larger when informal SMEs are included. The study report of World Bank Group estimates that there will be a requirement of 600 million jobs in the next 15 years to devour and be in pace with the growing world-wide workforce, primarily in Asia and Sub-Saharan Africa (Woldie and Mwita, 2012).

Over the time SMEs in Tanzania have played a crucial role in progressing Tanzanian economy by producing conditions favorable to employment opportunities, income production, equitable distribution of income along with contributing towards poverty mitigation (Woldie and Mwita, 2012). The SME sector in Tanzania, requires to be patted and pushed due to presence of various restraints curbing the development of the sector such as: Unfavorable legal and regulatory framework, Undeveloped infrastructure, Poor business development services, Limited access of SMEs to finance, Inadequate and ill organized institutional support framework etc (small and medium enterprise development policy, 2002).

The introduction of ICT in SMEs amounts to several innovative investment creating favourable circumstances within local industries. Tarute and Gatautis (2013) acknowledge the influence of introducing ICT in external and internal communication with an outcome of boosted performance, as such it is crucial to invest in ICT with internal ability and organizational processes. Olise at al., (2014) observed the stimulus of ICT adoption for enhanced SME performance and that there were important disparities in the levels of awareness and adoption patterns of ICT facilities among SMEs. The study on 'The Role of Technology as a Key Driver to SMEs Competitiveness - A Case of SMEs in Nairobi County' conducted by Dr. Johnester Ali Mwangulu (2015) concludes that technology possess huge potential for boosting market 
access and yet its usage in SMEs is limited. A large number of SMEs use ICT for communication, social networking, and general information procurement. Even today several studies conclude that there is a vacuum in awareness of the sphere of opportunities ICT brings to a firm much needed for enhanced market competitiveness. Defined use of ICT in SMEs can be associated with ascribed anticipated high costs of proper applications, security issues and limited or no knowledge and skills on few ICT applications like ecommerce. The readiness and feasibility of adopting e-HRM in the SMEs is relied on the availability of resources and the attitude of the workers including expertise, financial and technical resources (Hooi, 2007).

As already discussed the IT has incredible impact on the operation and practices of human resource management, as such examining the global demands and requirements in the digital era the HR managers are depending on E-HRM to actualize their functions. E-HRM reduces the administrative hardship for HR professional which further allows the HR to deliver excelling services to the organization's stakeholders such as employees, managers etc. For a successful beneficial edge it is very crucial to adopt E-HRM appropriately. The main determinants that work as challenges to the adoption of E-HRM are employee's individual attributes, top management support, IT infrastructure, compatibility, and industry pressure. Moreover in this tech-age the culture difference play a crucial role as influencing catalyst in adopting E-HRM (Masum, Kabir and Chowdhury; 2015). E-HRM adoption also faces challenges in terms of poor support and low budget by management which are not keen for setting aside financial plans for E-HRM system, ICT facilities and skilled training for employees. There is a lacuna in framing fair regulatory schemes including laws, regulations, policies and procedures for managing ICTs in the organization.

Despite the reality and evidence on the impact of adopting E-HRM system and its benefit to an organization, E-HRM has to encounter various challenges such as, cost implications, aligning E-HRM system with the business needs, security of the information, training the end users, etc. The initial funds required to adopt and implement the E-HRM may be too high and hence the organizations find E-HRM unaffordable and are reluctant to set aside budget. Implementing E-HRM, need skilled staff and E-HRM savvy employees which may be a problem in Tanzania. Even the TCAA (Tanzania Civil Aviation Authority) managers have been reported to have inadequate efficiency to accomplish the E-HRM system functions due to lack of ICT skills (Walinda, 2013). E-HRM technology development is influenced by several elements like- level of technology investment, top management decisions, involvement of employees, training, problems of policies etc. Organizations face several barriers in adopting and implementing E-HRM technology with major restraint like - high cost of software, deficiency or absence of expertise, lack of training and the dependability of the system and lack of management backing and infrastructures (Walinda, 2013).

The core barriers of HR are defining roles, inadequate resources, skill gaps, and incompetent technology. The leading three barriers to the HR to be lack of funds, lack of management support and poor and weak information technology systems (Mutahaba, 2015). Developing countries even today lack Information/evidence based decision making and fear to adopt it in organizations and face shortfall of personnel, equipment and financial resources required for information gathering, examination and analysis, promulgation and use. Moreover not all companies possess the latest and best technology, nor do all companies require the latest and advanced technology, but all companies do possess HR-related information requirements. Lining up of process in the HR activities to the prospective e-business is also another challenge. Other hurdles include lack of budget to acquire, update, and maintain crucial E-HRM, lack of expertise/s in IT to operate due to the hesitancy of the organizations to train, instruct and develop the employee. As per Madulu (2016) in his work on adoption of electronic record keeping for human resource management whose findings indicate that some obstacles of E-HRM in Tanzania include shortage of funds, unwillingness of user/employees to use new technology, poor accessibility etc. More so, Tanzania faces numerous challenges for use IT (URT, 2009). As per study by Walinda (2013) adoption and use of EHRM technology in Tanzania is faced with the major challenges and that emphasizing on implementation, use and development of E-HRM system technology in organizations will have great influence on overall performance and tackle challenges.

According to the current studies combined with the academic literature above, we conclude the following factors have great effect on attitude towards adopting E-HRM: behavioural, financial, organizational, governmental and technological. These are the important challenges towards adopting e-HRM. This information is vital when designing implementation methodologies and change management strategies as interventions need to be designed specially to meet the company's requirement of e-HRM adoption and implementation. Accepting that e-HRM obviously is not a strictly universal practice, it is appropriate for certain type of organizations while inappropriate for other organizations. The above findings and below figure (2), thus contribute to our understanding of the challenges of E-HRM adoption.

Figure 2: Research Framework 


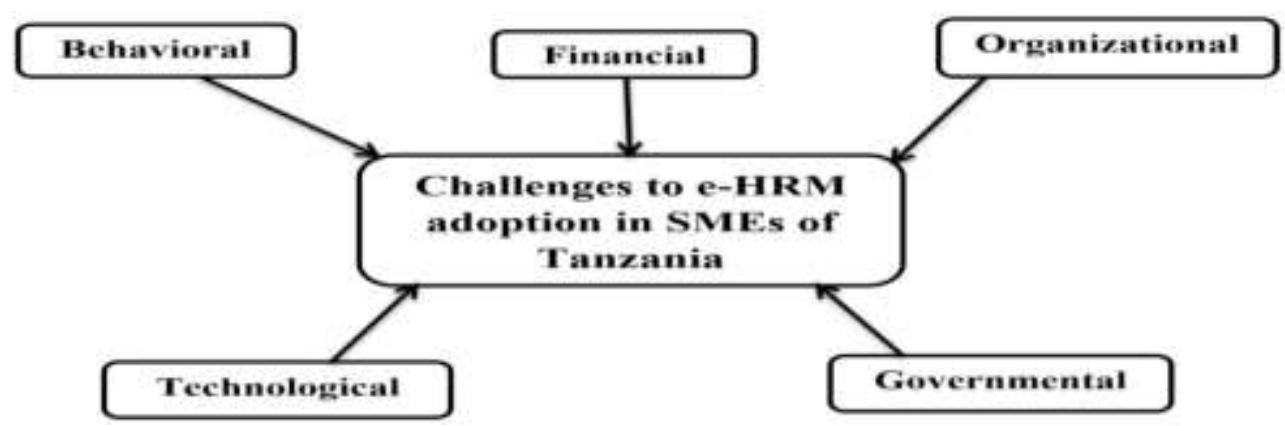

Source: From the Literature

\section{METHODOLOGY}

Little research has examined on the relationship between HR roles and E-HRM by adoption of TAM model. To date, there was one study examined the relationship between HR roles and E-HRM (Voermans and van Veldhoven, 2007), but it was conducted in Netherlands among 99 managers and 257 employees within Philips Electronics. They found that there were differences in perceived usability of current IT systems, as well as the preferred HR roles. For managers, user support was also found to be a predictor of a positive attitude towards E-HRM. In Malaysia, Ramayah et al. (2006) studied on the adoption and usage of a HRIS among HR executives and HR professionals working in companies in Penang. Their study revealed that compatibility and visibility were positively related and complexity was negatively related to extent of use of the HRIS. Despite the growing interest in TAM, empirical research on TAM, HR roles, and E-HRM has been limited and, hence more empirical research is called for. More research can, not only show the level of E-HRM adoption, but also identify obstacles and suggest ways to overcome it. Because E-HRM has received such scant attention in the literature, it is necessary to address the question of what antecedents contributes to challenges towards E-HRM adoption by looking at the literature representing disciplines other than E-HRM. In particular, TAM and model of HR roles will be used. Although there is a body of literature vis-à-vis SMEs barriers in adopting e-system, studies into the adoption and successful implementation of e-HRM in the Tanzania is comparatively new (Kabanda and Brown, 2015). Since SMEs are often acknowledged as the engine of national economic growth, it is relevant to investigate why SMEs in Tanzania have not taken up the many opportunities of e-HRM considering the rapid growth of technology in the developed countries.

To identify the extent to which the body of research literature has explored the challenges of e-HRM adoption, an extensive, topic based literature review was conducted following the principles of TAM and various other models were reviewed for synthesis. Google scholar was the key search engine due to its wide access to various journal databases on the study area, Articles were accessed from Emerald Insight, Research Gate, Sage pub, Academia, Wiley online library, Psych info, Semantic scholar and Jstor through University of Dar-es-salaam subscription. From about 24,240 hits on the internet, 282 abstracts relevant to the paper were found and reviewed for relevance. Finally, 72 documents were used in the study. The search of titles and abstracts was restricted to the time span between 1990 until 2019. Additionally, the volume of publications on this topic has rapidly increased over the last decade.

\section{ANALYSIS AND INTERPRETATION}

Despite its many conceptualizations, e-HRM adoption is considered vital and still lacks behind in developing countries. TAM model has played a key role in informing the development of the framework proposed for challenges of e-HRM adoption. TAM is selected to inform this study as it is most prominent result oriented and process oriented approach and is used in wide empirical literature. Behavioral intention is a degree of the force of one's intention to perform a stated behavior.

Figure 3: The Technology Acceptance Model, Davis (1989).

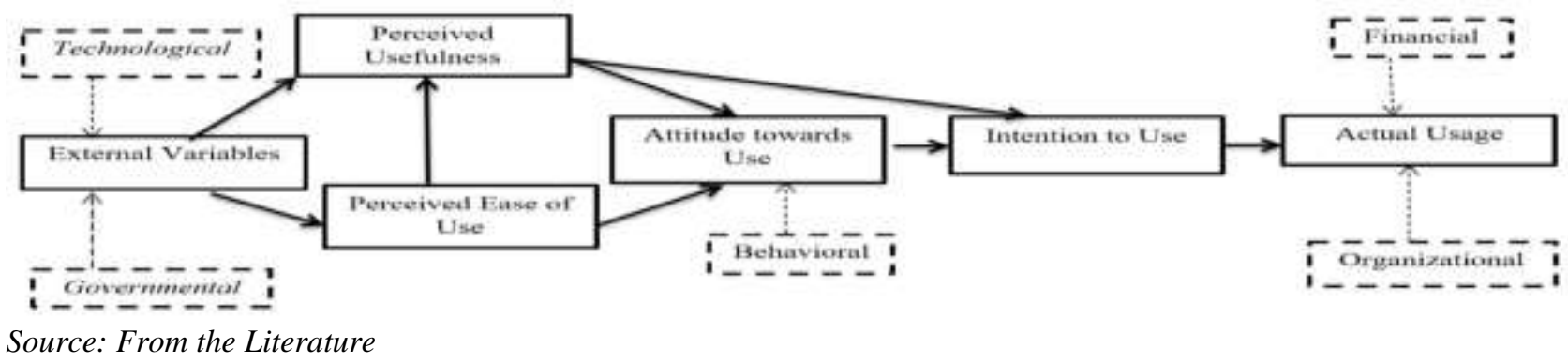

TAM is constructed on six constructs (Davis et al., 1989): actual system use, behavioral intention to use, attitude toward using, perceived usefulness, perceived ease of use and external characteristics. From these, the correlation among attitudes 
toward using, behavioral intention to use and actual system use were drawn from the theory of reasoned action (Davis et al., 1989). Perceived usefulness is expressed as the degree to which a person considers that using a specific technology will aid in executing a job well and improve the job performance (Davis et al., 1989). That is if the technology is not difficult to use, it can be extra constructive too (Davis et al. 1989). Perceived ease of use talks about "the degree to which the prospective user expects the technology to require the least amount of effort" (Davis, Bagozzi, and Warshaw 1989). There is a big chance that users will embrace the technology if the technology is easier to use, supposing that other variables are unvarying.

The impact of perceived usefulness on technology use was presented by the work of Schultz and Slevin (1975) and Robey (1979). As per technology acceptance model, perceived ease of use and perceived usefulness forecast the acceptance of information technology (Ma and Liu, 2004). TAM is a treasured tool for forecasting adoption, attitudes, satisfaction, and usage from beliefs and external variables (Algahtani and King, 1999).

Different studies have been guided by TAM for example, Pikkarainen, Pikkarainen, Karjaluoto and Pahnila (2004) applied the theory in their study to establish technology acceptance variables influencing online-banking experience in Finland while Porter and Donthu (2006), applied the theory to establish how attitudes determine Internet usage in Southeastern US metropolitan area. Lin, Fofanah and Liang (2011) applied it in their study on evaluating citizen embracing of electronicGovernment programs in Gambia. Chitungo and Munongo (2013) applied TAM theory framework in their analysis on mobile banking embracing in rural Zimbabwe. Erdogmus and Esen (2011) applied it to examination of the results of technology willingness on e-HRM. This theory has also therefore guided our study on e-HRM adoption challenges in Tanzania.

As per Mentz and Mentz (2003), any government and/or organization needs adoption and practice of IT as it provides a competitive edge to achieve national development and international IT collaboration; but for the successful launching and advancement of technology along with its implementation there is need of leadership and organization defined by an effective policy. In Tanzania lack of sufficient capital has resulted in either IT projects not initiated or totally banned as the cost of Information Technology are high, for its, development and maintenance. The nix-fix rigid policies of the government have high tariffs, duties and license fees that account to be soaring for investing in telecommunication and computer services (Ejiaku, 2014). Behavioural factors emphasises on the significance of the value generated by the use of a specific innovation or a technology system. As the knowledge of IT increases among the HR professionals, they are more positive towards the adoption of e-HRM. Technology knowledge gives them confidence to use e-HRM effectively. It was found that if the HR managers and employees have a good knowledge of IT they would be anticipating the adoption of a technology application in their HR department (Khatoon, 2012).

Table 1: e-HRM adoption challenges in Tanzanian SMEs

\begin{tabular}{|l|l|}
\hline Challenges & Items \\
\hline Behavioural & $\begin{array}{l}\text { ICT perceived not easy to use, e-HRM perceived not very useful, social influence, } \\
\text { lack of Leadership }\end{array}$ \\
\hline Financial & $\begin{array}{l}\text { Poor/lack of ICT budgets, high setting up costs, high buying costs, high maintenance } \\
\text { costs }\end{array}$ \\
\hline Organisational & $\begin{array}{l}\text { Lack of Management support, lack of skilled workers, lack of ICT knowledge, } \\
\text { difficult to change current working procedures }\end{array}$ \\
\hline Technological & $\begin{array}{l}\text { Lack technical knowledge, power cuts, inadequate infrastructure, inadequate speed } \\
\text { and quality of line }\end{array}$ \\
\hline Governmental & $\begin{array}{l}\text { Lack of policies for ICT adoption, economic and political instability, lack of legal } \\
\text { and regulatory system, lack of government leadership }\end{array}$ \\
\hline
\end{tabular}

Source: From the literature

The Mkukuta strategy (2006) expounded on the existence of inadequate complementary strategies and plans in Tanzania and defined the dire requirement for a fair development strategy along with a human resource development plan. The existing plans and policies were not framed keeping in mind the consequence encountered in the IT development, and were treated inadequately. Moreover with policies in place there is lack of implementation by capacity which is a problem for both technical and human making it weak (URT, 2014).

In Tanzania efforts to transform HRM operations from traditional, manual paper-based to electronic operations in government departments do exist but the implementation has been slow and is encountering several challenges (Mnjama $\&$ Wamukoya, 2007). As such in Tanzania E-HRM schemes implementation is lame and weak (International Development research, 2009). Despite of drafting the ICT policy (URT, 2003) and efforts by the government on adoption of IT, there is 
still a vacuum when it comes to implementing E-HRM system which identifies the existence of unclear and unsound policies addressing the developed pertaining selection of software system for use of ICTs within the organization Sajane (2004), further conclude the lack of clear policies, strategies and guidelines that work as barriers to E-HRM system implementation and development. The National ICT policy of 2003 requires to be frequently re-examined and revised to furnish a national framework that will stress on compatible use of technology by organizations so as to subsidize in achieving national development goals. Polices need to be amended to keep in pace with the world market and more efforts through government for implementation strategies and plans need to be framed and executed efficiently. Dynamic policies required to adopt the E-HRM system technology easily and to secure information are crucial for development of E-HRM system in Tanzania (Walinda, 2013). The SME sector is acknowledged to play an imperative role in the economic growth and development of Tanzania with regards to their GDP contribution and employment creation. However, the SME sector in Tanzania is yet to unleash their full potential due to these factors impeding their growth. Numerous studies have identified e-HRM as a tool for SMEs growth (Ameyaw and Modzi, 2016). This research investigating the factors of adoption of e-HRM will benefit SMEs and Tanzania as a whole.

\section{CONCLUSION AND RECOMMENDATIONS}

"Tanzania should have created a strong, diversified, resilient and competitive economy, which can effectively cope with the challenges of development and, which can also easily and confidently adapt to the changing market and technological conditions in the regional and global economy" (The Tanzanian Development Vision 2025).

Human resources are believed as the most expensive resource in any organization; thus, they need careful management. The goal of human resources management is to make certain that a company has the right number of people with the essential knowledge, skills, abilities and competencies, in the right place, at the right time, at an affordable cost and who are motivated and resolute to achieve the current and strategic need of a firm. E-HRM practice delivers a more efficient and strategic way of working to reach the goals. E-HRM aids human resource functions with the chance to create new roads for committing to organizational success. (Martin, Alexander, Reddington, and Pate, 2006). In order to meet the demands of today's knowledge-based economy, it is practically a must for companies to maximize the potential and productivity of their employees, a goal in the direction of which HRM information systems and E-HRM could be of help. Although there exists an avalanche of literature on e-HRM, its adoption and its implementation, relatively few studies have focused on SMEs in the developing countries like Tanzania. Addressing the gap in the literature, this study aimed to gain a clearer picture of the determinant factors that prevent Tanzanian SMEs from adopting e-HRM system. The research framework was drawn from issues relating to SMEs characteristic nature and e-HRM adoption. Numerous reasons have been outlined, including but not limited to, lack or inadequate financial resources, lack of e-HRM knowledge and the absence of important regulations and standards of e-HRM are mentioned challenges to e-HRM adoption and more. E-HRM possesses the potential to enhance how SMEs operates both internally and externally. Specifically, e-HRM increases cost efficiency enhances productivity and reinforces the possibilities of growth (Walinda, 2013). Moreover, the adoption of eHRM by SMEs can enrich business relationships and cooperation, quality and diffusion of knowledge. According to the related literature and the following deductions are drawn: The slow growth of E-HRM in developing countries like Tanzania is also due to seizure of power supply, insecurity amounting to slows down the measures of development as such no organization will set aside budget where the safety of his facilities is desolate. This amounts to slow penetration of IT with challenges like leadership development. Moreover transforming the traditional practice to E-HRM means implementing change in the complete system, this is a big challenge in the potent human society. Bureaucracy and introducing the requirements to bring transformation and doing things differently so as to eliminate bottlenecks and red tape is also a challenge (Oxford Business Group, 2019). Challenges also include the cost and intricacy of IT implementation, which many times demands important work process and cultural changes. Other elements that slow down the E-HRM adoption are the sources of funds required to cover the costs of setting up and maintaining IT, mobilization of financial resources, help from top management, training of staff on the operation of E-HRM, efforts to be put on attitude of staff to appreciate and accept the transformation towards IT, need of skills and opportuneness in the implementation stage and lack of strategies to consistently redefine and deliver improved return on investment in human capital to cope with excellent and poor economies and, new technology. Lack or poor drafting of policies essential to trigger additional investment amounts to encounter the probability of unforeseen outcomes like implementation failures due to organizations' impotence to build the essential cultural changes (Oxford Business Group, 2019).

As per Mercer's (2007) survey reports, among other ingredients that slow down the E-HRM adoption and inhibitors of HR changes the core hitch to HR transformation is the deficiency of skilled staff expertise which does concerns the inability to draft and instrument change programs and are reason to the absorptive capacity of innovative technology and knowledge. As such there is dire need to have skilled and trained staff at the very birth of transformation process. The availability of technology which forms the strength of any transformation, reliable and affordable support from pertinent technological system before launching HR transformation also cause issues to the organization in the long term. Other components that add to the slowing procedure of IT adoption are lack of support from the top management level, internal bureaucracy, poor funding for technology, the deficit of employee and business line buy-in, trouble in dealing with organizational and national cultures, employees' attitudes to the transformation, etc. (Ha, 2011). 
To fully harness the potential opportunities of e-HRM in the developing economy of Tanzanian SMEs and gain competitive advantage over their competitors in both the local and global markets, the following framework is recommended for further study:

Figure 4: Conceptual Framework for successful e-HRM adoption in developing nation

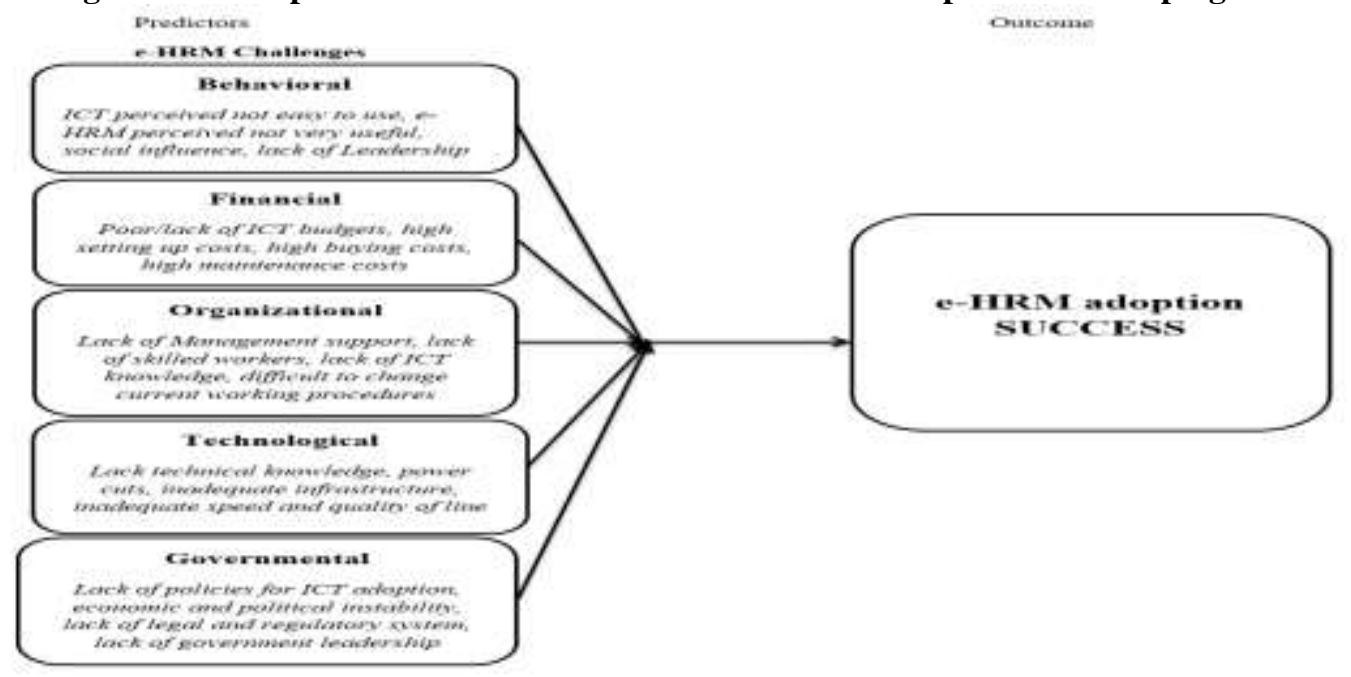

Source: From literature

This study highlights the potential challenges of e-HRM amongst Tanzanian SMEs and recommends framework for further studies to generalize and investigate the factors that expedite or impede successful e-HRM adoption.

\section{REFERENCES}

- Abdalkrim, G. M. (2012). The Impact of Human Resource management Practices on Organizational Performance in Saudi Banking Sector, Alsulial Salman Bin Abdulaziz University, Kingdom Of Saudi Arabia.

- Al-Gahtani, Said, S. and King, M. (1999). Attitudes, satisfaction and usage: factors contributing to each in the acceptance of information technology, Behaviour and Information Technology, 18, 4, 277- 297.

- Al-Najar, F. (2008). E-government between theory and practice, al dar al jameya, Alexandria, Egypt.

- Ameyaw B, Modzi SK. (1975) Government policies, internationalization and ICT usage towards SME's growth: An empirical review of Ghana. British Journal of Economics, Management and Trade. 2016;12(3):1-11.

- Anderson, W. (1997). The future of human resources: forging ahead or falling behind?, HumanResource Management, 36- 1, 17-22.

- Asogwa, B.E and Ezema, I.F. (2012). The Challenges of Preservation of Archives and Records in the Electronic Age. Pacific Northwest Library Association Quarterly, 76, 3.

- Banerji, S.C., (2013) A Study of Issues and Challenges of Implementation of Information Technology in HR. Global Journal of Management and Business Studies 3(4). 435-440.

- Beer, M. (1997), The transformation of the HR function: resolving the tension between atraditional administrative and a new strategic role, Human Resource Management, 3, 1, 49-56

- Chinyuka, A. M. (2018). Implementation of human capital management information system (hcmis) in local government authorities in Tanzania: a case of Moshi district council. Mzumbe University, Tanzania.

- Chitungo, S. K., and Munongo, S. (2013). Extending the technology acceptance modelto mobile banking adoption in rural Zimbabwe. Journal of Business Administration and Education, 3(1), 51-79.

- Cumming, K. (2010). Ways of seeing: contextualizing the continuum. Records Management Journal.

- Davis, F. D., and Arbor, A. (1989). Perceived usefulness, perceived ease of use, and user acceptance of information technology. MIS Quarterly, September.

- Davis, F. D., and Arbor, A. (1989). Perceived usefulness, perceived ease of use, and user acceptance of information technology. MIS Quarterly, September.

- Davis, F.D., Bagozzi, R.P. and Warshaw, P.R. (1989). User Acceptance of Computer Technology: A Comparison of Two Theoretical Models," Man- agement Science (35:8), 982-1003.

- Denver, M., Gibson M., Tonderayi N. And Severino M. (2018). Human Resource Management Practices: A Case of SMES in Zimbabwe. International Journal of Economics, Commerce and Management, 6(8).

- Dessler, G. (2013). Human Resource Management. 13th Edition. Pearson Education Limited. Essex, UK. 
- $\quad$ Ejiaku, S.A. (2014), Technology adoption: Issues and challenges in information technology adoption inemerging economies, Journal of International Technology and Information Management, 23, 2, 59-68.

- Ellig, B. (1997), Is the human resource function neglecting the employees?, Human Resource Management, 36, 1, 91-5.

- Ensher, E. A., Nielson, T. R., and Grant-Valone, E. (2002). Effects of the internet and technology on HR processes.Organizational Dynamics,31(3), 224-244.

- Erdogmus, N., and Esen, M. (2011). An investigation of the effects of technology readiness on technology acceptance in e-HRM. Procedia Social and Behavioral Sciences, 24, 487-495.

- Fisher, C.D., Schoenfeldt, L.F. and Shaw, J.B. (1996). An Introduction to Human Resource Management. Houghton Mifflin Company, Boston.

- Ha, N. T. V. (2011). The Impact of E-HRM on the Roles and Competencies of HR. Unpublished Master's Thesis in Management International Business. University of Vaasa, Faulty of Business Studies Department of Management.

- Hooi L., (2007). Implementing e-HRM: The Readiness of Small and Medium Sized Manufacturing Companies in Malaysia. Volume 12, 2006 - Asia Pacific Business Review . Issue 4: Business and Management in South East Asia: Studies in Diversity and Dynamism.

- International Records Management Trust. (2007). Tanzania case study: fostering trust and integrity in public sector information systems in the ICT environment. London: IRMT. http://www.irmt.org/documents/building_integrity/case_studies/IRMT_Case_Study_Tanzania.pdf

- Kabanda, S. K., and Brown, I. (2015). E-commerce enablers and barriers in Tanzanian small and medium enterprises. Electronic Journal of Information Systems in Developing Countries, 67(1), 1-24.

- Khashman, A. M. and Al-Ryalat, H. A. (2015). The Impact of Electronic Human Resource Management (E-HRM) Practices on Business Performance in Jordanian Telecommunications Sector: The Employees Perspective. Journal of Management Research, 7(3), 115-129.

- Khatoon, S., (2012). Adoption of E-HRM in Healthcare Services: An Empirical Study. Aligarh Muslim University.

- $\quad$ Khatoon, T., Amin, M.R., and Hossain, M. (2013). Strategic human resource management (SHR) practices and its effect on financial performance: evidence from some selected scheduled private commercial banks in Bangladesh. International Journal of Economics, Finance and Management Sciences, 1(3).

- Kochan, T. (1997), Rebalancing the role of human resources, Human Resource Management, 36, 1,121-7.

- Lengnick-Hall, M. L., and Moritz, S. (2003).The impact of e-HRM on the human resource management function. Journal of Labor Research, 24(3), 365-379

- Lepak, D.P., and Snell, S.A. (1998). Virtual HR: Strategic human resource management in the 21 st century. Human Resource Management Review, 8, 2 15-234.

- Lin, F., S. S. Fofanah, and D. Liang, (2011). Assessing citizen adoption of e-Government initiatives in Gambia: A validation of the technology acceptance model in information systems success. Government Information Quarterly, 28(2), 271-279.

- Ma, Q., and Liu, L. (2004). The technology acceptance model: A meta-analysis of empirical findings. Journal of Organizational and End User Computing, 16(1), 59-72.

- Madulu M., (2016). Adoption ofElectronic Record Keeping forHuman Resource ManagementatPresident's Office Regional Administration andLocal Governmentin Tanzania. Mzumbe University.

- Martin, G., Alexander, H., Reddington, M. and Pate, J.M. (2006). Using Technology to Transform the Future of HR: An Illustrated Model of E-HR. Proceedings of theAcademy of Management Annual Conference, Atlanta, 1216.

- Martin, G., and Reddington, M. (2010). Theorizing the links between e-HRM and strategic HR: A model, case illustration and reflections. The International Journal of Human Resource Management, 21.

- Masum A., Kabir M.,and Chowdhury M., (2015) Determinants that Influencing the Adoption of E-HRM: An Empirical Study on Bangladesh. Asian Social Science, 11, 21, 117-124.

- Mentz, E., and Mentz, K. (2003). Managing technology integration into schools: A South African perspective. Journal of Educational Administration, 41(2), 186-200.

- Mercer. (2007). HR Transformation 2.0: It's all about the business.

- Mnjama, N., and Wamukoya, J. (2007). E-government and Record Management: an assessment tool for e-records management in government. The Electronic Library, 25 (3), 274-284.

- Mondy, R and Noe, R (2005). Human resource management, 9th edn, Person Education International, New Jersey, USA. 
- Mukherjee A., Bhattacharyya S. and Bera R., (2014).0 Role Of Information Technology In Human Resource Management Of Sme: A Study On The Use Of Applicant Tracking System, Ibmrd's Journal Of Management And Research, Print Issn: 2277-7830, Online Issn: 2348-5922

- Mutahaba, G. (2015). Human Resource Management: A Neglected Element in African Public Service Reforms, A Tool for Developing Capacities for Managing the Human Resource in Africa's Public Sector Institutions. 73 87 .

- Nyame, P., and Boateng R., (2015). The Adoption and Use of Human Resource Information System (HRIS) in Ghana. International Conference on Enterprise Information Systems, 130-138.

- $\quad$ Olise M.C., Anigbogu T.U., Edoko T.D. and Okoli M.I. (2014). Determinants of ICT Adoption for Improved SME's Performance in Anambra State, Nigeria, American International Journal of Contemporary Research, 4(7), 163-176.

- $\quad$ Pikkarainen, T., Pikkarainen, K., Karjaluoto, H., and Pahnila, S. (2004), Consumer acceptance of online banking: An extension of the technology acceptance model, Internet Research, 14(3), 224-235.

- Porter, C.E. and Donthu, N. (2006) Using the TechnologyAcceptance Model to Explain How Attitudes Determine Internet Usage: The role of perceived access barriers and demographics. Journal of Business Research, 59, 9991007.

- $\quad$ Robey, D. (1979). User Attitudes and Management In- formation System Use, Academy of Management Journal (22:3), September 1979, 527- 538.

- Ruel, H., Bondarouk, T. and Looise, J. (2004). E-HRM: Innovation or irritation. An explorative empirical study in five large companies on web-based HR.Management Review, 15(3), 364-381.

- Sajane, L. (2004). An investigation into management of electronic records in the public sector. Journal of record management, 13-17.

- Schultz RL, Slevin DP (1975). Implementing operations research/management science. New York: American Elsevier

- Smale, A., and Heikkilä, J. P. (2009). IT-Based integration of HR in a foreign MNC subsidiary: A micro-political perspective. In Handbook of Research on E-Transformation and Human Resources Management Technologies: Organizational Outcomes and Challenge. 153-170

- Small And Medium Enterprise Development Policy (2002), United Republic Of Tanzania Ministry Of Industry And Trade, Chapter 2, -Sme Development In Tanzania

- Snell S., Stueber D.and Lepak D. (2002). Virtual HR departments: getting out of the middle.In:R. Henneman and D. Greenberger (Eds.), Human Resource Management in Vitual Organizations, Greenwich: Information Age Publishing.

- Strohmeier, S. (2007). Research in e-HRM: Review and implications. Human Resource Management Review, 17(1), 19-37.

- $\quad$ Sylvester, E.O.; Bamidele, A. and Oluyemi, O. (2015). Implementing E-HRM System in Developing Countries: Challenges and Prospects. International Journal of Applied Information Systems, 9(8).

- Tansley, C., Newell, S., and Williams, H. (2001). Effecting HR-style practices through an integrated human resource information system. Personnel Review, 30(3), 351.

- Tanzanin,Tanzania Development Vision 2025, The Government Printer, Dar es Salaam, 1999.

- Tarutėa A., and Gatautis R., (2013). ICT impact on SMEs performance. Contemporary Issues in Business, Management and Education

- Ukandu, E.N., Iwu, C.G. and Allen-1le, C.O.K. (2014). Influence of E-HRM in decision making in selected tertiary institutions in South Africa. Problems and Perspectives in Management, 12(4):397-405.

- Ulrich, D. (1997a). Judge me more by my future than by my past, Human ResourceManagement, 36 (1). 5-8.

- Ulrich, D. (1997b), HR of the future: conclusions and observations, Human ResourceManagement, 36 (1), 175 9.

- Ulrich, D. (1998), A new mandate for human resources, Harvard Business Review, 124-34.

- United Republic of Tanzania. (2009). Tanzania E-government Strategy. Dar es Salaam: President's Office - Public Service Management.

- Venkatesh, V. (1999). Creation of favorable user perceptions: exploring the role of intrinsicmotivation.MIS Quarterly,23,239-260.

- Voermans, M. and Veldhoven, M. V. (2007). Attitude towards E-HRM: an empirical study at Philips, Personnel Review, 36 (6), 887-902

- Walinda, S. R. (2013). Development of electronic human resource management for public institutions in Tanzania: a case of Tanzania civil aviation authority. Open university of Tanzania. 
Asian Journal of Business and Management (ISSN: 2321 - 2802)

Volume 8-Issue 4, October 2020

- Yeung, A. and Brockbank, W. (1995) Re-engineering HRthrough information technology. Human Re-source Planning, 18:2, 25-37. 